\section{Edycaçäa

ARTIGO

\section{Editores}

Maria Inês Côrte Vitoria

PUCRS, RS, Brasil

Pricila Kohls dos Santos

PUCRS, RS, Brasil

\section{Equipe Editorial}

Rosa Maria Rigo

PUCRS, RS, Brasil

\title{
Contribuições do Programa Institucional de Bolsas de Iniciação à Docência na formação continuada de professores supervisores
}

\author{
Contributions of Institutional Teaching Initiation Program in the \\ continued training of teachers supervisors
}

Jones Baroni Ferreira de Menezes ${ }^{a}$, Josefa Bento da Silva ${ }^{b}$

\section{RESUMO}

A formação continuada de professores faz parte de uma contínua necessidade de desenvolvimento profissional, levando os docentes a refletirem criticamente sobre a própria prática pedagógica. O presente trabalho objetivou investigar as contribuições do Programa Institucional de Bolsas de Iniciação à Docência (Pibid) na formação continuada de oito professores supervisores participantes dos subprojetos da Faculdade de Educação, Ciências e Letras de Iguatu, campi da Universidade Estadual do Ceará (FECLI/UECE). Esta investigação caracteriza-se como descritiva e exploratória, com abordagem qualitativa. Os dados foram coletados a partir de questionário e analisados de forma descritivo-interpretativa. Diante dos resultados, observou-se que o PIBID contribuiu de forma positiva e progressiva no tocante à formação continuada de professores supervisores, pirncipalmente no tocante à atualização dos conteúdos da área, bem como das metodologias e dos recursos pedagógicos que podem ser inseridos em sua rotina de sala. Assim, há uma práxis docente diante das experiências compartilhadas com bolsistas de Iniciação à Docência no recinto escolar, evoluindo-os e qualificando sua prática.

Palavras-chave: Docente; Metodologias de ensino; Política educacional; Formação.

\section{ABSTRACT}

Continuing teacher education is part of a continuing need for professional development, leading teachers to reflect critically on their own pedagogical practice. The present work aimed to investigate the contributions of the Institutional Program of Initiation Scholarships to Teaching (Pibid) in the continuous for mation of eight supervisors participating in the subprojects of the Faculty of Education, Sciences and Letters of Iguatu campi of 
the State University of Ceará (FECLI/UECE). This research is characterized as descriptive and exploratory, with a qualitative approach. Data were collected from a questionnaire and analyzed in a descriptive-interpretative manner. In view of the results, it was observed that the PIBID contributed in a positive and progressive way with regard to the continuous formation of supervising teachers, mainly in relation to the updating of the contents of the area, as well as the pedagogical methodologies and resources that can be inserted in their routine of living room. Thus, there is a teaching praxis in the face of the experiences shared with initiation scholarship students in the school, evolving them and qualifying their practice.

Keywords: Teacher. Teaching methodologies. Education policy. Formation.

\section{Introdução}

escola desempenha importante papel na sociedade contemporânea, estando presente em todas as etapas de formação do indivíduo ao longo da vida. Nesse sentido, é um espaço de aprendizagem, reflexão e investigação, não só dos educandos, mas de professores, núcleo gestor e de todos os profissionais que estão envolvidos no processo educacional (TARDIF e LESSARD, 2009).

Os professores são essenciais aos processos de mudança das sociedades. As decisões pedagógicas e curriculares sugeridas pelos técnicos em Educação ou em outras áreas devem ser efetivadas mediante a participação docente (IMBERNÓN, 2010). Assim, esse profissional exerce uma enorme função no desenvolvimento da construção do conhecimento do aluno, pois ele tem o papel de organizar, instruir e incentivar o estudante na busca pela própria aprendizagem, tornando-o, assim, agente ativo nesse processo.

Pimenta e Anastasiou (2002, p. 259) incentivam o desenvolvimento profissional mediante o preparo pedagógico, não separando os processos de desenvolvimento pessoal e institucional. Os docentes representam um dos maiores agrupamentos profissionais do país, estando grande parte alocados no setor público. Assim, o Estado tem a responsabilidade de propagar políticas públicas educacionais, almejando minorar as persistentes desigualdades regionais e alicerçando o desejo de uma educação pública de qualidade. Para tal, deve haver um constante incentivo na qualificação do magistério.

Dentro do contexto retrocitado, a docência é caracterizada como uma profissão que traz muitos desafios e conquistas ao longo da carreira. Seguindo o exposto, as formações continuada e contínua de professores são bastante discutidas entre estudiosos, governantes e nos congressos de ensino, visando à melhoria da capacitação 
dos profissionais que atuam na Educação. Gatti (2011) demonstra que as políticas de formação docente devem ser contempladas a partir do desempenho da escola na sociedade atual e do papel dos professores perante essa nova realidade que se descortina, em que educadores e alunos constroem o conhecimento por meio da reflexão sobre o mundo que os cerca.

Nos anos recentes, o governo federal vem tomando iniciativas de programas de formação inicial e continuada, em parcerias com as instituições de ensino superior públicas, particularmente em nível de universidades e institutos de ensino, e pesquisa federal e estadual (GATTI, BARRETO, ANDRÉ, 2011).

A formação continuada de professores, segundo Schnetzler (1996) e Nóvoa (1991), justifica-se pela necessidade contínua de desenvolvimento profissional, de reflexões críticas sobre a própria prática pedagógica e de superação do distanciamento entre as contribuições da pesquisa educacional e de sua utilização para a transformação da prática docente.

Partindo do princípio de que o professor é um agente transformador de opiniões e participa de forma direta no processo educacional, é de fundamental importância a participação desses regentes no processo de formação inicial de futuros docentes. Uma vez que é nesse processo que o professor em exercício pode vislumbrar sua prática de ensino de forma dialógica e significativa na formação de novos profissionais para atuar na área da Educação.

O Programa Institucional de Bolsa de Iniciação à Docência (Pibid) é uma ação para o aprimoramento e valorização da formação de professores para o Ensino Básico; Procura fortalecer a formação inicial e continuada e assim valorizar o magistério mediante a inclusão de alunos dos cursos de licenciatura ao dia a dia escolar através da pesquisa e da prática (BRASIL, 2009). Para que esse programa ocorra, é indispensável a participação de professores da Educação Básica (supervisores), que têm o papel de supervisionar e acompanhar os futuros docentes (bolsistas) no desenvolvimento das ações propostas, no decorrer do projeto nas escolas de Ensino Básico.

A aproximação entre universidade e escolas é um frutífero feito formativo, alicerçando a conexão entre os conhecimentos teórico e prático, singularmente no tocante à formação de professores. Já a formação entre/com educadores/as representa o compromisso de traduzir, na prática, o reconhecimento dos/as educandos/as e educadores/ as como sujeitos de conhecimento (FREITAS, 2017).

Pelo edital Capes/DEB n. 02/2009, a Universidade Estadual do Ceará (Uece) iniciou sua participação no programa com o projeto intitulado "A vida docente na escola: aprender e ensinar pela pesquisa". O foco era a aprendizagem da profissão docente mediante o contato direto dos licenciandos, bolsistas de iniciação à docência, com os fazeres característicos do trabalho docente no cotidiano escolar e seus dilemas (BRASIL, 2013). Nesse edital, a Fecli participou com os cursos de Ciências Biológicas, Física e Matemática. 
No edital no 001/2011/Capes, a Uece participa agora com o projeto de mesmo título, porém objetivando uma maior abrangência "pibidiana" na instituição e ampliando o número de campi e cursos participantes. Com isso, conta com 1.041 alunos bolsistas, 158 professores supervisores e 62 coordenadores de áreas, distribuídos em 29 subprojetos de licenciaturas nos campi da Uece (BRASIL, 2011). Já em 2013, os cursos de licenciatura contemplados na Fecli faziam parte dos subprojetos de Ciências Biológicas, Física, Matemática e Letras e contaram com 106 alunos bolsistas, 12 supervisores e sete coordenadores de áreas.

Diante da parceria da universidade com a escola, através da inserção do Pibid nas escolas da rede pública de ensino, indaga-se: quais as contribuições que o programa vem trazendo para o aprimoramento da formação continuada de seus professores supervisores? Nesse intuito, o trabalho objetiva investigar as contribuições do Pibid na formação continuada de professores supervisores dos subprojetos de Ciências Biológicas, Física e Matemática da Fecli, editais de 2009 e 2013. Analisa a concepção dos professores supervisores a respeito da formação contínua e sua participação em cursos de formação continuada e no Pibid, além de averiguar as novas metodologias de ensino utilizadas pelos professores supervisores ao interagirem com os bolsistas de iniciação à docência.

\section{Percurso metodológico}

Esta pesquisa caracteriza-se como descritiva, com abordagem qualitativa. Para Alvarenga (2012), a pesquisa descritiva está direcionada a designar como uma variável pode ser determinada em uma situação. Ademais, a referida autora define que a abordagem qualitativa "tenta descrever e compreender situações e processos de forma geral e profunda, considerando inclusive o contexto que envolve a problemática utilizada" (IBIDEM, p. 10).

Quanto aos sujeitos, são os professores supervisores do projeto Pibid da Faculdade de Educação, Ciências e Letras de Iguatu (Fecli/Uece), e dos subprojetos dos cursos de Ciências Biológicas, Física e Matemática da referida instituição, totalizando um número de oito professores da rede estadual de ensino. Adotando os seguintes critérios de admissão: professores supervisores que participaram dos editais de 2009 e 2011 e que estiveram disponíveis para a realização da pesquisa.

Para a efetivação da coleta de dados foi aplicado um questionário contendo seis questões objetivas e sete subjetivas, realizado durante os meses de setembro e outubro de 2014 e respondido de forma anônima. A análise dos dados foi verificada de acordo com sua particularidade. Os dados objetivos foram demonstrados em tabelas, e os dados subjetivos foram transcritos, analisados e comparados com outros autores do referido assunto. Desse modo, respeitando os preceitos éticos de "anonimicidade" dos sujeitos, os mesmos foram identificados alfabeticamente, através das letras A, B, C, D, E, F, G e H. 
Assim, seguiram-se as exigências éticas e científicas fundamentais, contidas na Resolução 466/12, que regulamenta as Pesquisas Envolvendo Seres Humanos. Todo projeto de pesquisa que se propõe a trabalhar com seres humanos apresenta implicações éticas que necessitam ser discutidas e adequadas para sua execução (BRASIL, 2012).

\section{Resultados e discussão}

\subsection{Caracterização dos sujeitos}

O presente trabalho foi realizado com oito professores supervisores participantes dos subprojetos Pibid/Fecli, sendo cinco do sexo masculino (M) e três do sexo feminino (F), com idade variando de 25 a 41 anos (Tabela 1).

Tabela 1. Caracterização dos sujeitos da pesquisa

\begin{tabular}{|c|c|c|c|c|c|}
\hline Professor(a) & Sexo & Idade & $\begin{array}{l}\text { Área de Formação } \\
\text { Profissional }\end{array}$ & Vínculo Empregatício & $\begin{array}{c}\text { Tempo de Magistério } \\
\text { na Escola }\end{array}$ \\
\hline Professor A & $\mathrm{F}$ & 39 & Biologia & Efetivo & Mais de 5 anos \\
\hline Professor B & $\mathrm{F}$ & 28 & Biologia & Temporário & Menos de 1 ano \\
\hline Professor C & $\mathrm{F}$ & 39 & Biologia & Efetivo & Mais de cinco anos \\
\hline Professor D & M & 41 & Biologia & Efetivo & Mais de cinco anos \\
\hline Professor E & M & 28 & Biologia & Efetivo & Entre 1 e 3 anos \\
\hline Professor $\mathrm{F}$ & M & 32 & Matemática & Efetivo & Entre 3 a 5 anos \\
\hline Professor G & M & 36 & Matemática & Efetivo & Mais de cinco anos \\
\hline Professor $\mathrm{H}$ & M & 25 & Física & Efetivo & Entre 1 a 3 anos \\
\hline
\end{tabular}

Fonte: Elaborada pelos autores.

Entre os pesquisados, observou-se que cinco fazem parte do subprojeto de Biologia, dois de Matemática e um de Física, tendo os mesmos a formação na sua respectiva área de atuação. Esse ponto vai ao encontro do que preconiza a Lei n. 9.394/96 (LDB), a qual ressalta que os trabalhadores da educação devem atuar em sua área pedagógica ou afim, daí a importância de o professor exercer o magistério no seu referido campo do conhecimento, motivo pelo qual ele precisa possuir domínio sobre os conteúdos científicos (SEVERINO, 2001). 
Quanto ao vínculo empregatício efetivo apresentado, sete professores o possuem na escola onde desenvolvem atividade como professores supervisores do Pibid. Entretanto, apenas um professor é contratado pelo Estado para desempenhar a função por tempo determinado. A forma de ingresso na carreira docente pública se dá através de concurso de provas e títulos para os cargos efetivos ou de seleção pública para os cargos temporários.

Também foi questionado o tempo de magistério na escola onde desenvolvem atividades do Pibid, e foi observado que quatro professores lecionam há mais de cinco anos; um professor, de três a cinco anos; dois professores, entre um e três anos; e apenas um professor, com menos de um ano, conforme também demonstrado na Tabela 1.

A relevância do tempo de docência é enfatizada por Tardif(2002), quando afirma que o conhecimento docente se estabelece, também, em função do tempo de exercício do magistério. Assim, a experiência em sala de aula, juntamente com um processo formativo contínuo, favorece a prática docente, seja no caráter pessoal, emocional, didático ou pedagógico.

\subsection{O processo de aperfeiçoamento na formação de professores}

Sobre a temática em questão, iniciou-se indagando aos professores sobre a participação em atividades extracurriculares durante a formação inicial, obtendo-se como resposta que somente um professor (professor A) não participou de nenhuma atividade; o professor B participou do Programa de Monitoria; o professor C, de Iniciação Científica; o D, de estágios extracurriculares; os professores E e G, de projetos de extensão; o F, de iniciação científica e estágios extracurriculares; e o $\mathrm{H}$, de monitoria e iniciação científica, conforme pode ser observado na Tabela 2.

Nesse interim, Fior e Mercuri (2009, p. 5) afirmam:

que os currículos da formação inicial devem ser sedimentados nas atividades vivenciadas pelos alunos e que as mesmas possam ter características obrigatórias, quando pertencerem ao conjunto de atividades que são previamente definidas como essenciais à conclusão do curso, quando não obrigatórias, caracterizadas pelas atividades vivenciadas pelos alunos dentro ou fora da sala de aula ou do espaço físico da universidade, nas quais existe uma maior autonomia do estudante na seleção das experiências com as quais se envolverá. Essas atividades podem ser ilustradas pela participação em monitoria, iniciação científica, nos órgãos de representação estudantil, em congressos e eventos científicos, entre outros. 
Tabela 2. Participação em programas durante o início da formação

\begin{tabular}{ll}
\hline Professor(a) & Participação \\
\hline Professor A & Nenhuma participação \\
Professor B & Monitoria \\
Professor C & Iniciação científica \\
Professor D & Estágios extracurriculares \\
Professor E & Projetos de extensão \\
Professor F & Iniciação científica e estágios extracurriculares \\
Professor G & Projetos de extensão \\
Professor H & Monitoria e iniciação científica \\
\hline
\end{tabular}

Fonte: Elaborada pelos autores.

Assim, faz-se necessário enfatizar que os estudantes compõem sua trajetória acadêmica também com as atividades não obrigatórias, o que favorece o desenvolvimento do profissional de ensino como um todo, já que a formação inicial dos professores deve ser compreendida como um momento em que ocorrem trocas de conhecimentos entre os formadores (de dentro e fora da universidade) e os que estão em formação (SCHIMIT e FREITAS, 2014).

Como todos os profissionais, o professor precisa fazer ajustes permanentes em suas ações, como forma de aperfeiçoar o processo de ensino e aprendizagem. Adicionalmente, Libâneo (2004) traz a indissociabilidade entre a formação inicial e continuada. Para o autor,

o termo formação continuada vem acompanhado de outro, a formação inicial. A formação inicial refere-se ao ensino de conhecimentos teóricos e práticos destinados à formação profissional, completados por estágios. A formação continuada é o prolongamento da formação inicial, visando o aperfeiçoamento profissional teórico e prático no próprio contexto de trabalho e o desenvolvimento de uma cultura geral mais ampla, para além do exercício profissional (idem, p. 227).

Nessa direção, a formação continuada tem função relevante, uma vez que as práticas apresentadas, as novas metodologias e formações visam a auxiliar na adaptação ao sistema de ensino, no embasamento dos novos aprendizados adquiridos nas universidades e na troca de experiências dentro do grupo, além de remeter a uma reflexão sobre as 
ações e metodologias praticadas (GLAT, MAGALHÃES e CARNEIRO, 1998). Assim, indagou-se sobre o conceito de formação "contínua" e se realizam/realizaram esse tipo de formação.

Como respostas, citaram que esse é um processo que se dá depois da formação inicial e se estende ao longo da vida do profissional, sendo permanente, assim como observado nas falas a seguir.

"É o processo de formação que se dá de forma progressiva, tendo como principal mecanismo a experiência vivida dentro do ambiente escolar que leva à reflexão e à mudança da prática pedagógica." (Professor B)

"É o processo contínuo de aprendizagem complementar à formação inicial. Através desta, é possível atualizar, rever, reconstruir, propor os conceitos e teorias existentes." (Professor C)

"As formações devem ser um momento para preenchermos lacunas da nossa formação acadêmica e para atualização e aperfeiçoamento da nossa prática pedagógica atendendo às necessidades das demandas de cada momento histórico da carreira docente." (Professor D)

"É um processo permanente de aperfeiçoamento da sua prática, qualquer que seja a profissão. No nosso caso, como professores, esta é imprescindível para o aprimoramento ou até mesmo para a transmissão da nossa prática pedagógica." (Professor F)

"No âmbito educacional, trata-se do prosseguimento do profissional na vida acadêmica mesmo após a graduação, ou seja, participação de cursos de extensão na modalidade EAD, etc.” (Professor H)

Isso corrobora com Lima (2001), ao enfatizar que essa formação não cessa, acontece ao longo da carreira docente, tornando-a contínua. $\mathrm{O}$ que demonstra que não se esgota na formação inicial, mas sucede em determinadas fases da história de seu magistério, tornando o professor um profissional crítico e reflexivo de sua prática pedagógica (VEIGA, 2011).

Desse modo, essa formação contínua se concretiza no âmbito educacional, através das novas experiências vivenciadas nas práticas educativas no cotidiano escolar. Para Nóvoa (1991), a formação deve estar articulada com a atuação profissional dos professores, tornando as escolas lugares de referência. Uma vez que é no cotidiano do trabalho docente que o professor se aperfeiçoa, constantemente, para dar conta dos conhecimentos que são transmitidos para os educandos. Assim, essa formação se concretiza, quebrando paradigmas da complexidade da carreira docente.

Sobre a participação em formação continuada, sete professores mencionaram que participaram nos seguintes cursos: Programa de Aperfeiçoamento para Professores de Matemática do Ensino Médio (Papmem); Curso de 
Extensão Elaboração de Projeto de Pesquisa em Educação, oferecido pela Coordenação Geral do Programa Pibid; Pacto pelo Fortalecimento do Ensino Médio (Pacto); Curso de Aperfeiçoamento para Pessoas com Deficiência Visual. E dois professores citaram a participação em cursos de pós-graduação. Apenas um professor mencionou que não participou de nenhum curso após a sua entrada no Programa Pibid. Observa-se, então, que a maioria dos professores pesquisados busca o aprimoramento da carreira docente.

A formação continuada de professores de Ciências e, consequentemente, o enriquecimento de sua ação docente, desloca-se a partir de duas necessidades básicas, como afirma Selles (2000, p. 13):

[...] num pólo encontra-se a necessidade de atualizar e ampliar os conhecimentos científicos, num mundo em constante e rápida transformação científico-tecnológica; em outro, situa-se a necessidade de informação e envolvimento na discussão sobre as questões educacionais, uma vez que não é possível conceber um ensino de Ciências isolado do contexto educacional. Complementam estes dois eixos, um conjunto de subsídios teórico-metodológicos capazes de auxiliar a ação do professor na sala de aula e dentro da escola, na execução de trabalhos com seus parceiros institucionais.

Assim, o desenvolvimento profissional docente é um processo continuado, recorrente e inacabado, fazendo com que a formação contínua tenha um impacto positivo no âmbito educacional, trazendo novas experiências para as práticas educativas no cotidiano escolar e tornando as escolas lugares de referência, de modo a favorecer o processo de ensino e aprendizagem (NÓVOA, 1991; SELLES, 2000).

Com base no supraescrito, foram analisadas as possíveis sugestões no sentido de melhorar a formação continuada desses profissionais. Nesse rumo, os professores ilustraram como possíveis alternativas: melhoria e a valorização da carreira docente, melhor remuneração, mais tempo para o planejamento das atividades, momentos de troca de experiências com professores de outras escolas, redução da carga horária de trabalho, cursos mais atrativos e participação em eventos científicos. O que é demonstrado nas falas abaixo:

"Capacitações voltadas para cada área do conhecimento; estimular o professor a ser um pesquisador e oportunizar o profissional a outras qualificações como mestrado e doutorado.” Professor C)

"Cursos mais atrativos e que realmente desperte no professor a necessidade de mudar para melhorar suas práticas pedagógicas.” (Professor A)

"Usar procedimentos que estimulem os professores a serem pesquisadores e reflexivos; oportunizar momentos para trocar experiências com os professores de outras escolas." (Professor D) 
Conforme o apontado acima, são muitas as contribuições no tocante à melhoria da formação; assim, as instituições de ensino superior, as escolas, o Ministério da Educação (MEC) e outros sistemas de ensino devem ser parceiros na continuidade desse processo.

Nessa direção, Paiva e Taffarel (2001) demonstram que a universidade é o lugar privilegiado da produção e intervenção do saber sistematizado, do exercício da reflexão, do debate e da crítica, tornando-se um espaço para o interesse na busca do conhecimento contínuo.

\subsection{Contribuiçóes do Pibid na prática docente dos supervisores}

Questionou-se sobre o tempo de participação no programa como professor supervisor, tendo dois professores das áreas de ciências (Biologia) respondido que o tempo de participação era superior a três anos, demonstrando uma experiência maior quanto à vivência no projeto; dois professores citaram que seu tempo era entre um a dois anos, sendo os dois do curso de Matemática; e quatro professores apontaram seu tempo no projeto como menos de um ano, sendo três professores de Biologia e apenas um de Física.

Em seguida, foi perguntado sobre quais as contribuições do programa na formação continuada dos professores, sendo percebida uma contribuição positiva e significativa.

“O Pibid está sendo fundamental para que eu reflita sobre minha formação. A participação em semanas universitárias, congressos, roda de saberes, palestras têm contribuído muito para despertar a necessidade de uma busca pelo aprimoramento. Enquanto, supervisora, fiz uma especialização e agora meu próximo passo será o mestrado." (Professor A)

"O Pibid contribui de forma significativa para a reflexão da minha prática pedagógica, uma vez que me incentiva a pesquisar sobre a prática docente.” (Professor B)

"Através do Pibid foi possível aproximar-me das discussões acadêmicas, tendo em vista que após assumir a docência no Ensino Médio surge um distanciamento entre o Ensino Básico e o Ensino Superior." (Professor C)

"Proporcionou uma maior disponibilidade para desenvolver trabalhos científicos, participação de encontros e eventos." (Professor E)

"As contribuições foram: reacender o gosto pela leitura e trabalhar o ensino pela pesquisa. Apesar de desenvolver um bom trabalho em sala, eu quero e procuro continuar melhorando; troca de experiências com professores de outras escolas." (Professor D) 
“Após: ingresso no Pibid como supervisor, tive que aprofundar meus conhecimentos sobre PCNs, LDB e PNE para poder repassar aos alunos licenciandos." (Professor $\mathrm{H}$ )

"O contato com os futuros colegas professores (licenciandos bolsistas) do Pibid tem me proporcionado um "oxigênio" novo ao longo da minha caminhada enquanto professor, pois é notável que todas as atividades desenvolvidas pelos bolsistas têm proporcionado aulas mais dinâmicas. Os alunos vêm se mostrando mais motivados, pois, além da pesquisa, trabalhamos o reforço com os alunos, utilizando materiais práticos, concretos e atrativos construídos pelos próprios bolsistas, tais como jogos, gincanas, exploração de software, que sem dúvida têm tornado a aprendizagem mais significativa.” (Professor F)

“Melhor aproximação com a universidade. Maior esclarecimento com os cursos do MEC.” (Professor G)

É sabido que muitos profissionais da educação, após o término do curso de graduação, não retornam à universidade para a complementação dos conhecimentos. Assim, constatou-se, de acordo com os relatos, que o Pibid aproximou os supervisores da universidade através da participação em congressos, apresentações de trabalhos científicos, participação em bancas de monografias e rodas de saberes. Sendo evidente o estímulo do projeto à pesquisa e trocas de novos conhecimentos no tocante ao desempenho profissional.

Corroborando com esses dados, Paredes (2012) mostra que os professores-supervisores ressaltam que o Pibid auxilia no desenvolvimento profissional, principalmente como retomada de estudos e pesquisa na área educacional. Assim, os supervisores, ao se envolverem com o programa, inserem-se num movimento de formação continuada por meio de cursos e em desenvolvimento de projetos na escola junto com os licenciandos (NEITZEL, FERREIRA e COSTA, 2013).

Com base nisso, torna-se notório que, ao entrar no rograma, o professor retorna ao mundo acadêmico, dando continuidade aos seus estudos em nível de pós-graduação lato e stricto sensu. Ainda convém ressaltar o enriquecimento em seu currículo e no processo de interação e a atualização das novas ações que o programa propõe na formação de seus professores. Desse modo, o Pibid contribuiu no envolvimento do professor, nas pesquisas acadêmicas, pois as mesmas apresentam importância na formação continuada e no desempenho do professor, pois tem-se destacado a necessidade de se formar um docente investigador, reflexivo e crítico (SANTOS, 2001).

Aliado a isso, para Sacristan (2000), os professores buscam compreensão do que observam, sendo orientados da leitura de mundo dentro da perspectiva crítica e reflexiva da educação permanente.

Outro ponto a ser discutido é o aspecto positivo do contato entre os professores supervisores e os licenciandos bolsistas, o que tem proporcionado ao longo do projeto um novo ânimo na prática docente, além de um novo "fazer" pedagógico. Esse fato corrobora com o citado por Paredes (2012), o qual afirma que as novas propostas didáticas 
desenvolvidas pelos bolsistas contribuem para que o professor-supervisor também possa utilizá-las em suas práticas, fazendo-os refletir sobre sua própria prática docente.

$\mathrm{O}$ aprofundamento dos conhecimentos sobre a legislação educacional brasileira, principalmente no que tange aos Parâmetros Curriculares Nacionais (PCN), à Lei de Diretrizes e Bases da Educação (LDB) e ao Plano Nacional de Educação (PNE) é uma contribuição do Pibid. Nesse âmbito, o professor encontra-se em constante busca do aperfeiçoamento, da construção de novos saberes, pois, ao estudar sobre os principais documentos que regem a educação brasileira, ele volta a aprimorar seus conceitos sobre o magistério.

Quando questionados sobre o comprometimento dos professores com os bolsistas, foi averiguado como eles se avaliam enquanto supervisores. Assim, de acordo com as falas descritas abaixo, é possível observar que eles se sentem responsáveis pela formação dos bolsistas licenciandos.

"Atuo como protagonista da formação docente, pois, através das minhas experiências em regência de sala de aula, contribuo de forma significativa na formação inicial dos futuros colegas de trabalho, Sempre procuro estar refletindo sobre minha prática e buscando reinventá-la." (Professor D)

"Disposto a orientar de perto os bolsistas na construção de suas práticas docentes." (Professor F)

"Ainda tenho pouca experiência, mas até o momento busco desenvolver as atividades propostas pelo subprojeto da melhor forma possível." (Professor E)

“(...) sempre busquei atender às solicitações do subprojeto em prol de envolver os bolsistas da escola par que os mesmos pudessem entender o verdadeiro sentido do projeto.” (Professor C)

Observou-se nas falas dos supervisores que sua atuação é excelente, e que estão sempre dispostos para orientação e acompanhamento nas atividades propostas, assim mostrando para os bolsistas o entendimento do verdadeiro sentido do projeto.

Neitzel, Ferreira e Costa (2013, p. 5) complementam as falas dos sujeitos, afirmando que:

os professores supervisores, que atuam na rede como os responsáveis pela sua introdução no cotidiano escolar, são designados para supervisionar as atividades dos bolsistas de iniciação à docência. Eles acompanham as atividades presenciais dos licenciandos, ao mesmo tempo, que orientam os projetos a serem desenvolvidos nas escolas, participam de seminários, reuniões, atividades de formação, avaliação e reflexão pertinentes ao programa. Esses profissionais, ao se envolverem com o Programa, se inserem num movimento de formação continuada por meio de cursos e em desenvolvimento de projetos na escola junto com os licenciandos. 
Arroyo (2010, p. 163) também enfatiza que "o conhecimento, os valores e as competências se aprendem no intercâmbio humano", cujos atores envolvidos no projeto interagem e comprometem-se mutuamente.

Sobre a influência da inserção dos universitários na escola, observou-se que os bolsistas trouxeram mudanças na práxis docente de seus respectivos supervisores, por meio da mudança de postura em sala, renovação na reconstrução de novos conceitos, contextualização de suas aulas, aprofundamento nos conhecimentos na área de atuação, conforme as falas abaixo:

"A convivência e o trabalho com os alunos bolsistas do Pibid me proporcionaram um "gás" novo nessa caminhada onde estou constantemente vivenciando novas metodologias e compartilhando experiências." (Professor F)

"Sim, a dinâmica é outra, o profissional tem que estar atento nas suas práticas pedagógicas, pois os discentes estão em formação e você precisa ser exemplo para eles. Dessa forma os bolsistas passam a ver o supervisor como suporte na sua formação docente." (Professor C)

"A inserção de alunos universitários na escola contribuiu ainda mais para me tornar o sujeito da investigação, tornando-me o agente de mudanças, pois, através da aplicação da tese, faço a antítese e a síntese com o senso crítico para adaptar o método conforme a realidade vivenciada na comunidade escolar." (Professor D)

Nesse quesito, o Pibid influencia os professores supervisores na mudança da prática docente, fazendo-os refletir sobre sua prática, tornando o seu próprio trabalho de sala de aula um espaço de aprendizagem docente e de transformação humana (FERREIRA, 2008).

A partir disso, eles passam a elaborar estratégias mais atrativas no ensino dos componentes curriculares, participação em eventos científicos internos e externos, organização de eventos na escola, ampliação da percepção estética do espaço escolar e, também, podem buscar a parceria dos pais nas atividades escolares (NEITZEL, FERREIRA e COSTA, 2013).

\subsection{Metodologias de ensino utilizadas no cotidiano}

E, por fim, questionou-se em relação às diversificadas metodologias de ensino inseridas pelos bolsistas durante a participação no projeto. Observou-se uma diversidade de métodos utilizados: aulas laboratoriais, oficinas, aulas práticas, jogos educativos, atividades lúdicas, biogincanas, paródias, experimentos, palestras, debates, pesquisa em sala de aula, seminários, projetos de pesquisa, uso pedagógico do laboratório de informática, leituras de textos. O que demonstram as falas a seguir. 
"No projeto, temos a oportunidade de trabalhar com materiais concretos (jogos, software) que tornam a aprendizagem mais significativa para todos." (Professor F)

"O uso de jogos e atividades lúdicas certamente são metodologias que devem ser implantadas nas práticas docentes de qualquer professor.” (Professor H)

"Sim, como já citei na questão anterior. Por exemplo: jogos didáticos, gincanas, aulas práticas debates, leituras de textos, etc." (Professor A)

A inserção dos bolsistas (Pibid) trouxe metodologias diferenciadas à prática docente de seus supervisores. Por meio dos relatos acima, foi possível diagnosticar que todos são beneficiados, desde os alunos até o professor em sala, já que as aulas se tornam mais atrativas e dinâmicas, saindo da rotina.

Para Menezes e colaboradores (2014), as metodologias pedagógicas alternativas tornam a aprendizagem dos conteúdos mais eficaz, pois saem do modelo tradicional de ensino e fazem com que os alunos estabeleçam seu próprio entendimento sobre o assunto.

Assim, ao trabalharem com diversas estratégias e abordagens didáticas, os licenciandos e professores da rede pública compreendem melhor como ensinar Ciências, já que certos conteúdos são de difícil aprendizagem pelos alunos (CARVALHO e GIL-PÉREZ, 2000).

Dentre as metodologias destacadas pelos respondentes, cita-se o uso de jogos didáticos, com os quais os alunos interagem com os conteúdos de forma lúdica. Rosito (2008) destaca a importância destes para a aprendizagem dos alunos, assim como Baiotto e Della Méa (2009, p. 6) afirmam que esse recurso

fornece estas informações aos professores e estimula-os a trabalhar de forma mais dinâmica e atualizada e possibilita o desenvolvimento de aulas mais interessantes no Ensino Médio. A atividade lúdica permite ainda a introdução e a discussão de conceitos atuais e pertinentes ao ensino de biologia. (...) Além disso, os recursos utilizados na produção do material didático utilizado são de baixo custo e não exigem um moderno laboratório ou grande investimento para sua aplicação, contribuindo desta forma para que a escola cumpra seu papel de transmitir o conhecimento socialmente produzido.

Outra metodologia utilizada são as gincanas promovidas pelos bolsistas do Pibid. Na sociedade atual, o ato de brincar e jogar se opõe ao trabalho, o que tem motivado a pouca utilização dessas ferramentas pela maioria dos educadores (MURCIA, 2005). Porém, o papel do lúdico na aprendizagem é extremamente importante, assim Silva et al. (2013, p.7-8) afirmam em seu trabalho que a proposta de uma "gincana de ciências traz para a sala de aula 
'movimento', quebrando o paradigma de que para a construção do conhecimento é necessário apenas giz, lápis e caderno".

Outro método de ensino é o baseado em projetos, que permite uma aprendizagem colaborativa, investigativa e reflexiva, na qual o supervisor passa a interagir com alunos, comunidade escolar e equipe do Pibid na busca de melhoraria na aprendizagem dos alunos:

O trabalho com projetos permite uma aprendizagem colaborativa, tornando a relação ensino-aprendizagem um processo dinâmico, possibilitando a formação de sujeitos participativos e autônomos, criando a possibilidade de desfazer a forma de aula tradicional em que só o professor fala e apresenta os conteúdos e os alunos ficam restritos a escutar, copiar, memorizar e repetir os conteúdos (BEHRENS, 2007, p. 47).

É importante relatar também que esse tipo de metodologia baseia-se no princípio da experimentação no ensino de Ciências, a qual também é considerada propícia à aprendizagem científica.

A inserção dos recursos tecnológicos nos espaços educativos também é utilizada como forma de dinamizar o processo de ensino e está associada à produção de conhecimentos potencialmente diferenciados, pois permite abordar problemas de forma mais atrativa e contextualizada (ALMEIDA e MORAN, 2005).

Sartori e Roesler (2007, p. 102) definem que "a mídia e suas linguagens como agentes culturais que participam da aprendizagem, ainda que educandos não tenham acesso a equipamentos tecnológicos sofisticados, alimenta processos coletivos que surgem de uma prática pedagógica”.

A partir do exposto, evidenciou-se que a influência das novas propostas metodológicas inovadoras repercute diretamente nas aulas dos professores supervisores por meio de experiências compartilhadas nesse espaço formativo. Assim, é importante destacar que esse tipo de formação contemplada pelo programa propicia uma formação continuada dos professores supervisores, mesmo não sendo o objetivo principal do Pibid. É processo formativo docente pautado nas trocas de conhecimentos e no convívio com os bolsistas, universidade e coordenadores do projeto.

\section{Considerações finais}

Diante dos resultados obtidos, observou-se que o Pibid contribuiu de forma positiva e progressiva no tocante à formação continuada de professores supervisores, mediante as experiências compartilhadas com bolsistas de Iniciação à Docência no espaço escolar. Embora não seja o foco do programa a formação continuada, a pesquisa realizada apontou que o Pibid tem potencializado a adoção de métodos diversificados pelos professores supervisores, fortalecendo sua prática pedagógica. 
Desse modo, o Pibid incorpora um novo processo de formação continuada, no qual os supervisores não ficam detidos apenas em cursos com curta duração, mas atuam como agentes protagonistas na formação inicial de licenciandos, por meio das trocas de conhecimentos, metodologias inovadoras, participando ativamente da pesquisa e da prática docente.

Assim, esses supervisores renovam suas aulas através da inserção do bolsista aprendiz no saber docente, buscam novos métodos de ensino e materiais didáticos, e o Pibid revigora uma formação continuada, a partir da realidade vivenciada do contexto escolar.

Os supervisores, ao participarem do projeto, voltam à Instituição de Ensino Superior (IES) em busca de aprimorar os conhecimentos na área, ganham um novo ânimo, ou seja, trazem um novo entusiasmo no tocante à carreira docente, provocando mudanças significativas em sua prática docente. Esses docentes também atuam como modelos para os acadêmicos quando iniciarem suas práticas profissionais, florescendo sua própria identidade profissional.

\section{Referências}

ALMEIDA, Maria Elizabeth Bianconcini de; MORAN, José Manuel. Integração das tecnologias na educação. Brasília: Ministério da Educação, 2005.

ALVARENGA, Estelbina Miranda. Metodologia da investigação quantitativa e qualitativa. 2. ed. Assuncion: Grafica Sab, 2012.

ARROYO, Miguel Gonzalez. Ofício de mestre: imagens e autoimagens. 12. ed. Petrópolis: Vozes, 2010. Disponível em: <http://www. editorarealize.com.br/revistas/conedu/trabalhos/Modalidade_1datahora_14_08_2014_16_05_37_idinscrito_3036_45d18385660a9bac f45b064e6ff403dd.pdf>. Acesso em: 3 de mar. 2015.

BAIOTTO, Cléia Rosani; DELLA MÉA, Adriana Riguer. A produção de jogos didáticos para o ensino de genética: uma proposta para favorecer a aprendizagem. Cataventos - Revista de Extensão da Universidade de Cruz Alta, n. 1, 2009.

BEHRENS, Marilda Aparecida. A. Metodologia de projetos: o processo de aprender a aprender. In: TORRES, P. L. (Org.). Algumas vias para entretecer o pensar e o agir. Curitiba: Senar-PR, 2007.

BRASIL. Coordenação de Aperfeiçoamento de Pessoal Superior (Capes). 2013 Disponível em: <http://www.capes.gov.br>. Acesso em: 2 de fev. 2015.

Resolução no 466, de 12 de dezembro de 2012. Disponível em: <http://conselho.saude.gov.br/resolucoes/2012/Reso466.pdf>. Acesso em: 8 fev. 2015.

. Edital do Programa Institucional de Bolsa de Iniciação à Docência - Pibid. 2011. Disponível em: <http://www.uece.br/pibid/ dmdocuments/Proposta\%20Institucional\%20UECE\%202011.pdf>. Acesso em: 5 maio 2014.

. Edital do Programa Institucional de Bolsa de Iniciação à Docência - Pibid. 2009. 
Programa Institucional de Bolsa de Iniciação à Docência. 2009. Disponível em: <http://www.capes.gov.br/educacao-basica/ capespibid>. Acesso em: 5 maio 2014.

. Lei no 9.394, de 20 de dezembro de 1996. Lex: Leis de Diretrizes e Bases da Educação Brasileira (LDB), Brasília, 1996.

CARVAlHO, Ana Maria Pessoa de; GIL-PÉREZ, Daniel. Formação de professores de Ciências. 4. ed. São Paulo: Cortez, 2000.

FERREIRA, Liliana Soares. Gestão do pedagógico, trabalho e profissionalidade de professoras e professores. Revista Iberoamericana de Educación, n. 45, p. 217-228, 2007.

FIOR, Camila Alves; MERCURI, Elizabeth. Formação universitária e flexibilidade curricular: importância das atividades obrigatórias e não obrigatórias. Psicologia da Educação, n. 29, p. 191-215, 2009.

FREITAS, Ana Lúcia Souza de. Paulo Freire e Maurice Tardif: um diálogo de referências para fortalecer a articulação universidade escola na perspectiva da formação com educadores/as. Remea - Revista Eletrônica do Mestrado em Educação Ambiental, ed. esp., p. 25-39, 2017.

GATTI, Bernardete Angelina; BARRETO, Elba Siqueira de Sá; ANDRÉ, Marli Eliza Dalmazo de Afonso. Políticas docentes no Brasil: um estado da arte. Brasília: Unesco, 2011.

GLAT, Rosana; MAGALHÃES, E. F. C. B.; CARNEIRO, Rogéria. Capacitação de professores: primeiro passo para uma educação inclusiva. Perspectivas multidisciplinares em educação especial (p. 373-378). 1998.

IMBERNÓN, Francisco. Formação continuada de professores. Tradução Juliana dos Santos Padilha. Porto Alegre: Artmed, 2010.

. Formação docente e profissional: formar-se para a mudança e a incerteza. 2. ed. São Paulo: Cortez, 2001 (Coleção Questões da Nossa Época, v. 77). Disponível em: <http:/www.uninove.br/PDFs/Mestrados/Educa\%C3\%A7\%C3\%A3o/Anais_VII_Coloquio/ Manuela\%20Sousa_nao\%20timbrado.pdf>. Acesso em: 2 fev. 2015.

LIBÂNEO, José Carlos. Organização e estão da escola - teoria e prática. Goiânia: Alternativa, 2004.

LIMA, Maria Socorro Lucena. A formação contínua do professor nos caminhos e descaminhos do desenvolvimento profissional. Tese (Doutorado em Educação) - Universidade de São Paulo, São Paulo, 2001.

MENEZES, Jones Baroni Ferreira; SILVA, Josefa Bento; ALENCAR, Maria Mirtes Rodrigues; LEMOS, Adna Ferreira; MARTINS, Maria Márcia Mele Castro; SILVA, Ricardo Rodrigues; SILVA, Fernando Roberto Ferreira. Metodologias alternativas para o ensino de evolução e ecologia: uma experiência de bolsistas do Programa de Bolsas de Iniciação à Docência (Pibid) da Fecli/Uece. In: Anais do Congresso Nacional de Formação de Professores, Águas de Lindoia, 2014.

MURCIA, Juan Antônio Moreno. Aprendizagem através do jogo. Porto Alegre: Artmed, 2005.

NEITZEL, Adair Aguiar; FERREIRA, Valéria Silva; COSTA, Denise. Os impactos do Pibid nas licenciaturas e na educação básica. Conjectura: filosofia e educação, v. 18, n. esp., p. 98-121, 2013.

NÓVOA, Antonio. Concepções e práticas da formação contínua de professores: In: NÓVOA, A. (Org.). Formação contínua de professores: realidade e perspectivas. Portugal: Universidade de Aveiro, 1991. 
. (Org.). Os professores e sua formação. Lisboa: Dom Quixote, 1992.

. Os professores e as histórias da sua vida. In:

(Org.). Vidas de professores. Porto: Porto Editora, 1995.

PAIVA, Andréia Carla de; TAFFAREL, Celi Nelza Zulke. Profissionais da educação física e esportes: formação e prática - uma análise da produção acadêmica de 1996 a 2001. In: Anais do XII Congresso Brasileiro de Ciências do Esporte, 2001. CD-ROM.

PAREDES, Giuliana Gionna Olivi. Um estudo sobre o Pibid: saberes em construção na formação de professores de Ciências. 2012. Dissertação (Mestrado em Educação em Ciências e em Matemática) - Universidade Federal do Paraná. Programa de Pós-Graduação em Educação em Ciências e em Matemática. 2012. 183 f. Disponível em: <http://www.ppgecm.ufpr.br/Disserta\%C3\%A7\%C3\%B5es/009_ GiulianaGionnaOlivi aredes.pdf>. Acesso em: 20 dez. 2015.

PIMENTA, Selma Garrido; ANASTASIOU, Léa das Graças Carmargo. Docência no ensino superior. São Paulo: Cortez, 2002.

ROSITO, Berenice Alvares. O ensino de Ciências e a experimentação. In: MORAES, R. (Org.). Construtivismo e ensino de Ciências: reflexões epistemológicas e metodológicas. Porto Alegre: EdiPUCRS, 2008.

SACRISTAN, Jose Gimeno. A educação que temos, a educação que queremos. In: IMBERNON, Francisco (Org.). A educação do século XXI: os desafios do futuro imediato. Porto Alegre: Artemed, 2000.

SANTOS, Luciola. Dilemas e perspectivas na relação ensino e pesquisa. In: ANDRÉ, Marli (Org.). O papel da pesquisa na formação e na prática de professores. Campinas: Papirus, 2001.

SARTORI, Ademilde; ROESLER, Jucimara. Mídia e educação: linguagens, cultura e prática pedagógica. In: TORRES, P. L. (Org.). Algumas vias para entretecer o pensar e o agir. Curitiba: Senar-PR, 2007.

SCHIMIT, Magda; FREITAS, Deisi Sangoi. A participação em projetos de pesquisa durante a graduação em Pedagogia e sua contribuição para a formação docente: um relato autobiográfico. In: FÓRUM INTERNACIONAL DE PEDAGOGIA, VI., 2014, Santa Maria/RS. Disponível em: <http://editorarealize.com.br/revistas/fiped/trabalhos/Modalidade_2datahora_24_05_2014_08_31_36_idinscrito_649_ fe1ace422287563fb82ac564daab7cbb.pdf>. Acesso em: 28 fev. 2015.

SCHNETZLER, Roseli Pacheco. Como associar ensino com pesquisa na formação inicial e continuada de professores de Ciências? In: ENCONTRO REGIONAL DE ENSINO DE CIÊNCIAS, 2., 1996, Piracicaba. Atas... Piracicaba: Unimep, 1996. Vol. 1, p. 27-35.

SELLES, Sandra Escovedo. Formação continuada e desenvolvimento profissional de professores de Ciências: anotações de um projeto. Ensaio - Pesquisa em Educação em Ciências, v. 2, n. 2, p. 1-15, 2000.

SEVERINO, Antônio Joaquim; PIMENTA, Selam Garrido. Apresentação da coleção. In: DELIZOICOV, Demetrio; ANGOTTI, Jose Andre; PERNAMBUCO, Marta Maria. Ensino de Ciências: fundamentos e métodos. 2. ed. São Paulo: Cortez, 2007. p. 11-19.

SEVERINO, Antonio Joaquim. Educação, sujeito e história. São Paulo: Olho d'Água, 2001.

SILVA, Carla Melo; MERTINS, Simone; DOS SANTOS, Grace Oliveira Paim; SORGETZ, Clara Denise; ROBAINA, Jose Vicente Lima; DA SILVA Monica Galon; MONTIPÓ, Alessandra Medianeira. O lúdico na prática educativa: gincana de Ciências. Encontro de Debates sobre o Ensino de Química, v. 1, n. 1, 2013. 
SILVA, Ana Maria Costa. A formação contínua de professores: uma reflexão sobre as práticas e as práticas de reflexão em formação. Educação \& Sociedade, v. 21, n. 72, p. 89-109, 2000.

TARDIF, Maurice. Saberes docentes e formação profissional. Petrópolis, RJ: Vozes, 2002.

TARDIF, Maurice; LESSARD, Claude; GAUTHIER, Clermont. Formação dos professores e contextos sociais. Porto: Rés, 2001.

TARDIF, Maurice; LESSARD, Claude. O trabalho docente: elementos para uma teoria da docência como profissão de interações humanas. 5. ed. Rio de Janeiro: Vozes, 2009.

VEIGA, Ilma Passos; AMARAL, Ana Lucia (Org.). Formação de professores: políticas e debates. 5. ed. Campinas: Papirus, 2011.

Recebido em: agosto/2017

Aceito em: outubro/2017

\section{Endereço para correspondência:}

Av. Dr. Silas Munguba, 1700 - Campus do Itaperi

60741-000 Fortaleza, CE, Brasil

<jones.baroni@uece.br> 